\title{
An inexpensive and reliable new haemoglobin colour scale for assessing anaemia
}

\author{
S M Lewis, G J Stott, K J Wynn
}

\begin{abstract}
Aim-To describe a new inexpensive method (the WHO Colour Scale) for estimating haemoglobin concentration from a drop of blood by means of a colour scale, and to compare its reliability with a standard laboratory method of measuring haemoglobin, and its clinical usefulness in field trials.
\end{abstract}

Methods-The new colour scale method was used to measure haemoglobin concentration in 1213 random venous blood samples from routine work in four laboratories (one each in the UK, South Africa, Thailand, and Switzerland). Limited field trials of the method for assessing clinical usefulness were done in a rural hospital (in South Africa) staffed by nurses, at two blood donor sessions (one each in South Africa and Thailand), and by nonlaboratory personnel in malaria clinics (in Thailand), following training and a short practice session.

Results-In the laboratory based comparability study the presence of anaemia was reliably detected using the new method with $91 \%$ sensitivity and $86 \%$ specificity. Clinically relevant levels of anaemia (mild to moderate, pronounced, and severe) were graded and serious anaemia $(<8 \mathrm{~g} /$ dl) was identified with an efficiency of $89 \%$. The clinical trials showed the ease and reliability with which the colour scale could be used by non-laboratory persons after brief training. The blood donor trials showed it to be at least as reliable as the copper sulphate method with the advantage of being more convenient.

Conclusions-The preliminary studies have shown that the WHO Colour Scale is a reliable screening method for detecting anaemia, especially for diagnosing serious

Accepted for publication 10 October 1997 anaemia. Following a brief training session health workers found it simple to use and, at a cost of about 1/10th that for traditional photometric analysis, it should be of value in "countries in need" for primary health centres, obstetrical management, paediatric clinics, tropical disease control programmes, blood transfusion donor selection, as well as for industrial health checks and epidemiological studies.

(f Clin Pathol 1998;51:21-24)

Keywords: anaemia; haemoglobinometry; WHO

The worldwide prevalence of anaemia points to the importance of having a reliable method for its detection and for measuring its severity, both for epidemiological surveys and for the clinical management of patients. Twenty years ago a World Health Organisation consultation on haematology emphasised the need for a simple, cheap, and robust device for measuring haemoglobin concentration, capable of being used reliably by health workers outside the laboratory, and often in the absence of electric power. ${ }^{1}$ Several devices have been developed, but those that are reliable and accurate are generally expensive, and those that are inexpensive are generally unreliable. However, we believed that if a device based on direct comparison of fresh blood with a reliable colour scale could be developed it would provide a useful function in primary health care.

We studied the various factors responsible for the wide margin of error occurring with the available colour scales, including their design and mode of use, the colours employed, and the suitability of their test papers. ${ }^{2}$ Having identified these factors and considered how to overcome them we proceeded, with support from the WHO Programme on Health Technology, to develop a new colour scale.

The qualities required of the absorbent material were rapid absorbency of the blood drop with immediate loss of sheen and uniform colour spread without undue interference from fibres of the material, especially at low haemoglobin concentrations. After extensive trials it was concluded that Whatman 31ET Chr paper (Whatman International, Maidstone, Kent, UK) and Schleicher and Schuell 2992 paper (D-37582, Dassel, Germany) gave the best results (table 1). Test strips of $45 \times 15 \mathrm{~mm}$ were prepared from a batch of the Whatman paper.

To develop a suitable range of colours for the scale, a set of standards was established from

Characteristics refer to features observed when one drop of blood (haemoglobin $15.6 \mathrm{~g} / \mathrm{dl}$ ) in a syringe was added through a 23 SWG needle.

W, Whatman; S\&S, Schleicher \& Schuell. 


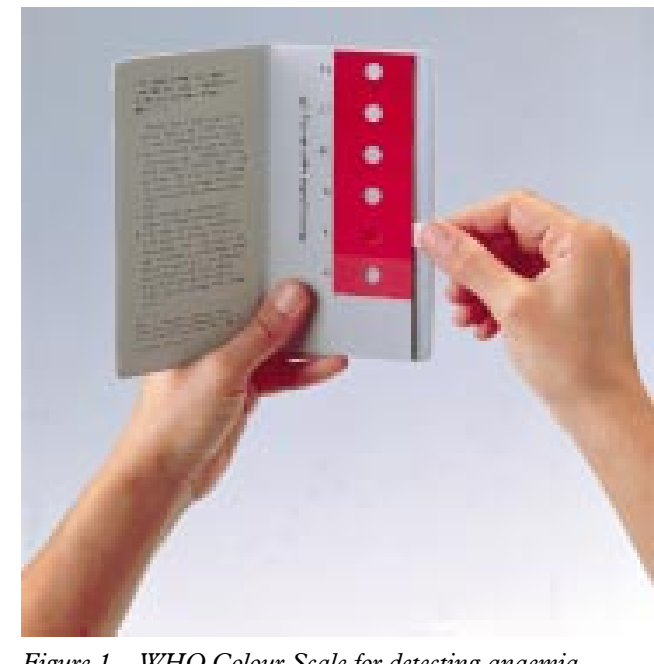

Figure 1 WHO Colour Scale for detecting anaemia.

blood samples with haemoglobin concentrations measured by spectrometry with the International Council for Standardization in Haematology reference method. Haemoglobin concentration was adjusted to obtain a range of $4-14 \mathrm{~g} / \mathrm{dl}$, in $1 \mathrm{~g} / \mathrm{dl}$ steps $(\mathrm{g} / \mathrm{dl}$ rather than in $\mathrm{g} / 1$ was chosen as the potential users of the scale are in general more familiar with this traditional unit). The spectral characteristics of the colour produced by a drop of blood on a test strip were identified by a computerised analytic spectrometer. These specifications were reproduced in printing inks prepared from the three primary colours and a neutral diluent using advanced technology pigments to obtain a high level of light fastness. The colour shades were printed at defined ink thickness on a specialist paper that was chemically neutral, unbleached, and chlorine free to avoid premature aging or yellowing that could affect the ink colour. The colours of the scale have not faded when exposed continuously for several months to daylight, including direct sunshine.

The six colour shades in $20 \times 40 \mathrm{~mm}$ strips were mounted with a neutral grey surround

Table 2 Multicentre trial comparing haemoglobin colour scale and reference method

\begin{tabular}{|c|c|c|c|c|c|c|c|c|}
\hline \multirow[b]{2}{*}{$\begin{array}{l}\text { Colour scale } \\
(\mathrm{g} / \mathrm{dl})\end{array}$} & \multirow[b]{2}{*}{ Total } & \multicolumn{7}{|c|}{ Reference ( $g / d l)$} \\
\hline & & $<4$ & $\begin{array}{l}4 \text { to } \\
<6\end{array}$ & $\begin{array}{l}6 \text { to } \\
<8\end{array}$ & $\begin{array}{l}8 \text { to } \\
<10\end{array}$ & $\begin{array}{l}10 \text { to } \\
<12\end{array}$ & $\begin{array}{l}12 \text { to } \\
<14\end{array}$ & $\geqslant 14$ \\
\hline$<4$ & 60 & 36 & 22 & 2 & 0 & 0 & 0 & 0 \\
\hline 4 to $<6$ & 124 & 22 & 80 & 20 & 2 & 0 & 0 & 0 \\
\hline 6 to $<8$ & 130 & 0 & 10 & 90 & 29 & 1 & 0 & 0 \\
\hline 8 to $<10$ & 260 & 0 & 1 & 68 & 143 & 39 & 5 & 4 \\
\hline 10 to $<12$ & 160 & 0 & 0 & 2 & 42 & 88 & 24 & 4 \\
\hline 12 to $<14$ & 250 & 0 & 0 & 3 & 18 & 55 & 140 & 34 \\
\hline$\geqslant 14$ & 229 & 0 & 0 & 1 & 6 & 32 & 85 & 105 \\
\hline
\end{tabular}

Table 3 Anaemia screening and diagnosis of severity of anaemia when present

\begin{tabular}{lllll}
\hline \multicolumn{5}{c}{ Colour scale readings $(g /$ dl $)$} \\
\cline { 2 - 5 } Reference haemoglobin $(\mathrm{g} / \mathrm{dl})$ & $\begin{array}{l}\text { Not anaemic } \\
(\geqslant 12)\end{array}$ & $\begin{array}{l}\text { Mild/moderate } \\
(8 \text { to }<12)\end{array}$ & $\begin{array}{l}\text { Pronounced } \\
(6 \text { to }<8)\end{array}$ & $\begin{array}{l}\text { Severe } \\
(<6)\end{array}$ \\
\hline$\geqslant 12$ & 364 & 37 & 0 & 0 \\
8 to $<12$ & 111 & 312 & 30 & 2 \\
6 to $<8$ & 4 & 70 & 90 & 160 \\
$<6$ & 0 & 1 & 10 & 94 \\
Sensitivity (\%) & 91 & 69 & 48 & 99 \\
Specificity (\%) & 86 & 86 & 96 & 97 \\
Efficiency (\%) & 87 & 79 & 89 & \\
\hline
\end{tabular}

onto a central rigid white PVC backing. For comparing colour of the blood stain with that of the scale a circular aperture of $8-9 \mathrm{~mm}$ diameter was punched in the centre of each colour standard. The scale was then enclosed in a protective cover of rigid PVC (fig 1). This construction ensures that the device is strong enough to be used many hundreds of times without excessive wear and tear even under field conditions.

\section{Results}

PRELIMINARY TEST IN REFERENCE CENTRES A feasibility test was done on blood samples over a wide range of haemoglobin concentrations, comparing the colour scale with spectrometric measurement. ${ }^{2}$ Best results for colour matching were obtained with the light coming over the shoulder of the observer, the light source being daylight (but not direct bright sunshine), artificial tungsten or fluorescent light. The correlation coefficient was 0.9386 , slope $=0.944$, intercept $=0.72(\mathrm{~g} / \mathrm{dl})$, and there was no significant difference in the means by $F$ ratio $(1.011$ at $v=26)$. These results were sufficiently encouraging to proceed further.

On the premise that the device is intended for detecting anaemia and for assessing its severity in clinical terms, trials were carried out in four centres with 1213 observations on random venous blood samples on which the haemoglobin had been measured by a routine laboratory method. The four centres were the Royal Postgraduate Medical School, London (S M Lewis); the South African Institute for Medical Research, Johannesburg (Professor B V Mendelow); the Ramathibodi Hospital, Mahidol University, Bangkok (Dr R Suwannuruks); and WHO, Geneva (G J Stott) with the collaboration of the Hôpital Universitaire de Geneve (Dr Ph Beris).

Participants included doctors, nurses, laboratory technicians, research scientists, medical students, and lay persons who were given a demonstration of the device followed by a short practice session. In each centre over a period of two to three weeks blood samples were coded and presented in a random order for reading the colour match. Where the colour of the stain lay between two shades they were asked to record the lower value. Results were analysed to assess the use of the scale for identifying prevalence and severity of anaemia in $1 \mathrm{~g} / \mathrm{dl}$ steps, and to assess its clinical usefulness using the statistical method described by Galen and Gambino (tables 2 and 3). ${ }^{3}$ Anaemia (haemoglobin $<12 \mathrm{~g} / \mathrm{dl}$ ) was diagnosed with an efficiency of $87 \%$. The severity of anaemia was graded in categories appropriate for clinical practice (table 4) and serious anaemia (haemoglobin $<8 \mathrm{~g} / \mathrm{dl}$ ) was diagnosed with an efficiency of $88 \%$, increasing to $97 \%$ when the concentration was $<6 \mathrm{~g} / \mathrm{dl}$ (table 3 ).

Some participants initially gave discrepant results but these improved with familiarisation. To investigate interobserver variation, readings were taken from 10 samples after an initial demonstration but without a practice session and then repeated by the same observers after practice with batches of control samples. There 
Table 4 Severity of anaemia

\begin{tabular}{ll}
\hline Haemoglobin $(\mathrm{g} / \mathrm{dl})$ & \\
\hline$\geqslant 14$ & Normal (men) \\
$\geqslant 12$ & Normal (women) \\
10 to $<12$ & Mild anaemia \\
8 to $<10$ & Moderate anaemia \\
6 to $<8$ & Marked anaemia \\
4 to $<6$ & Severe anaemia \\
$<4$ & Very severe anaemia requiring \\
& urgent attention
\end{tabular}

Table 5 Correlation with measurements by standard method

\begin{tabular}{llll}
\hline & Intercept & Slope & Correlation \\
\hline First use & 1.27 & 0.87 & 0.8867 \\
After training & 0.36 & 1.05 & 0.9734
\end{tabular}

was significant improvement in obtaining consistent results and better comparability with the correct values (table 5). This highlighted the need for some training; accordingly, a protocol for a training session together with instructions for using the scale have been produced. Intraobserver reproducibility was shown by two observers performing five sequential readings on each sample - the SD was less than $1 \mathrm{~g} / \mathrm{dl}$ (table 6).

FIELD TRIALS

A small batch of the colour scale was manufactured and used in limited field trials.

Rural health centre

As a model to test the feasibility of using the scale in field conditions, a study was carried out at the Tintswalo Rural Hospital in Mpumalanga Province, South Africa. ${ }^{4}$ The observers were five nurses, four medical students, and two lay people. Two batches of blood samples were provided, one with stated haemoglobin values for a training session, and a second batch of 20 test samples with haemoglobin concentrations from $2-17 \mathrm{~g} / \mathrm{dl}$, as determined by a reference laboratory with the haemiglobincyanide method.

The participants were given a general description of the colour scale and were shown the correct method of use, after which they practised under supervision. Within 30 minutes they were ready to use the colour scale on the test samples.

The participants varied in their ability to use the scale. Parametric analysis gave correlation coefficients ranging from 0.863 to 0.962 ; how-

Table 6 Reproducibility of readings

\begin{tabular}{lllr}
\hline \multirow{3}{*}{$\begin{array}{l}\text { True haemoglobin } \\
\text { (g/dl) }\end{array}$} & \multicolumn{3}{l}{ Scale reading* } \\
\cline { 2 - 4 } & Mean & $S D$ & $C V \%$ \\
\hline 4 & 4.25 & 0.45 & 10.6 \\
6 & 6.16 & 0.57 & 9.2 \\
7 & 6.9 & 0.56 & 8.2 \\
8 & 8.07 & 0.86 & 10.6 \\
10 & 10.0 & 0.85 & 8.5 \\
11 & 10.6 & 0.65 & 6.1 \\
12 & 12.3 & 0.51 & 4.1 \\
13 & 13.0 & 0.66 & 5.1 \\
14 & 13.8 & 0.57 & 4.1 \\
16 & $>14 \dagger$ & & \\
\hline
\end{tabular}

^Two observers, five separate readings by each; when a match occurred between two colours the intermediate value was recorded. $\dagger$ in $10 / 10$ readings. ever, using the means of the readings by all participants in each group, the correlation coefficient improved to 0.9500 for the nurses, 0.9570 for the lay people, and 0.9792 for the students. Overall, there was no significant difference between the reference method and the scale as analysed by $\mathrm{F}$ ratio (1.0198 at $\mathrm{v}=99)$; $t$ test on means showed $85-90 \%$ probability of no significant differences.

\section{Blood donor screening}

The scale was used in a limited feasibility study at blood donor sessions in South Africa and Thailand on 113 donors. Scale readings of $\geqslant 12 \mathrm{~g} / \mathrm{dl}$ for women and $\geqslant 14 \mathrm{~g} / \mathrm{dl}$ for men were graded as suitable and these measurements were compared with the traditional copper sulphate method. There were no discrepancies between the two methods, demonstrating the potential value of the colour scale as it has the advantage of being simple to use, does not require renewal at frequent intervals, and when a donor is anaemic the haemoglobin concentration is known immediately.

\section{Malaria clinics}

A prototype of the colour scale was used at three malaria clinics in Thailand as part of a WHO international training course on the control of malaria and other tropical diseases. A total of 148 patients were included in the study. At two of the clinics where the malaria parasite infection rate for those attending the clinic was $42 \%, 36 \%$ had pronounced to severe anaemia (haemoglobin $<10 \mathrm{~g} / \mathrm{dl}$ ), whereas in the third clinic where there was only $10 \%$ malaria positivity only $2 \%$ had haemoglobin concentrations $<10 \mathrm{~g} / \mathrm{dl}$. This indicates the usefulness of the colour scale in analysing the impact of malaria in endemic areas. ${ }^{5}$

\section{COSTING}

Current estimates for the production cost of the device suggest that it will provide the facility for estimating haemoglobin concentration for clinical purposes at about $1 / 10$ th the cost of traditional photometric analysis.

\section{Conclusions}

These studies have shown the reliability of the WHO Colour Scale in detecting anaemia and assessing its severity. The colour scale method is intended as a clinical resource and not as competition for standard haemoglobinometry. In the various circumstances in which its use is indicated it is less important to attempt to obtain a precise measurement of haemoglobin than to establish what clinical action is required.

There were some discrepancies between the colour scale results and a standard laboratory method, resulting mainly from inconsistencies in applying the drop of blood to the test strips but also to incorrect handling of the scale. Errors can be reduced significantly with a brief training period and by strict adherence to the instructions provided with the device. It is then possible to obtain results with a clinically efficient level of sensitivity and specificity. 
Following the laboratory based validation, preliminary feasibility studies were carried out that showed that the device is likely to be of particular value in "countries in need" for primary health centres, obstetrical management, paediatric clinics, malaria and hookworm control programmes, blood transfusion donor selection, industrial health checks, and epidemiological surveys of anaemia. A batch of the scales and test strips has been made for a multicentre study with independent investigators in a number of these areas. The present limited supply is being used for selected multicentre studies. On completion of these studies WHO will seek funding to make the colour scale and test strips available for global distribution through the appropriate channels within the organisation at a cost that will ensure that the price is kept to a minimum.
In addition to colleagues who participated in the preliminary test at the four preliminary field trial centres, we are indebted to Dr S Field, South African Blood Transfusion Service, Johannesburg, and Dr R Suwannuruks, Ramathibodi Hospital, Bangkok for the blood donor studies; Dr P F Beales, WHO

Tropical Diseases Control Division for the malaria studies. The study was funded in part by the World Health Organisation, Geneva. Dr Stott was formerly a consultant, Programme on Health Technology, World Health Organisation, Geneva.

1 World Health Organisation. Report of consultation on standardization in haematology. Document LAB/75.3. Geneva: WHO, 1975

2 Stott GJ, Lewis SM. A simple and reliable method for estimating haemoglobin. Bull World Health Organ 1995;73: $369-73$.

3 Galen RS, Gambino S. Beyond normality. The predictive value and efficiency of medical diagnosis. New York: Wiley, 1975.

4 Munster M, Erasmus LK, Mendelow BV, et al. Field evaluation of a novel haemoglobin measuring device designed for use in a rural setting. S Afr Med $71997 ; 87 ; 1522-6$.

5 Beales PF. Anaemia in malaria control: a practical approach. Ann Trop Med Parasitol 1997;91:713-18. 